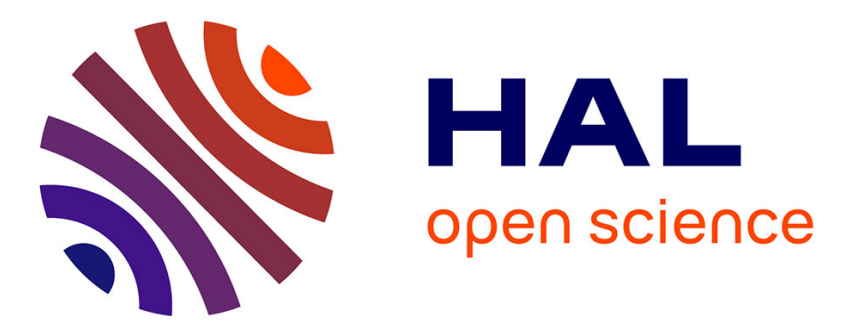

\title{
Outcome of isolated agenesis of the corpus callosum: A population-based prospective study
}

Vincent Des Portes, Anne Rolland, Juan Velazquez-Dominguez, Emeline

Peyric, Marie-Pierre Cordier, Pascal Gaucherand, Jérôme Massardier, Mona

Massoud, Aurore Curie, Anne-Sophie Pellot, et al.

\section{To cite this version:}

Vincent Des Portes, Anne Rolland, Juan Velazquez-Dominguez, Emeline Peyric, Marie-Pierre Cordier, et al.. Outcome of isolated agenesis of the corpus callosum: A population-based prospective study. European Journal of Paediatric Neurology, 2018, 22 (1), pp.82 - 92. 10.1016/j.ejpn.2017.08.003 . hal-01796396

\section{HAL Id: hal-01796396 \\ https://hal.umontpellier.fr/hal-01796396}

Submitted on 13 Jan 2020

HAL is a multi-disciplinary open access archive for the deposit and dissemination of scientific research documents, whether they are published or not. The documents may come from teaching and research institutions in France or abroad, or from public or private research centers.
L'archive ouverte pluridisciplinaire HAL, est destinée au dépôt et à la diffusion de documents scientifiques de niveau recherche, publiés ou non, émanant des établissements d'enseignement et de recherche français ou étrangers, des laboratoires publics ou privés. 


\title{
Outcome of isolated agenesis of the corpus callosum: A population-based prospective study
}

\author{
Vincent des Portes ${ }^{a, d, e, *}$, Anne Rolland ${ }^{a, g, h}$, Juan Velazquez-Dominguez ${ }^{a}$, \\ Emeline Peyric ${ }^{a}$, Marie-Pierre Cordier ${ }^{b}$, Pascal Gaucherand ${ }^{c, d}$, \\ Jérôme Massardier ${ }^{c}$, Mona Massoud ${ }^{c}$, Aurore Curie ${ }^{a, d, e}$, \\ Anne-Sophie Pellot ${ }^{f}$, François Rivier ${ }^{g, h}$, Audrey Lacalm ${ }^{i}$, Amélie Clément ${ }^{a}$, \\ Dorothée Ville ${ }^{a}$, Laurent Guibaud ${ }^{d, i}$
}

a Centre de référence "Déficiences Intellectuelles de causes rares ", Hôpital Femme Mère Enfant, Hospices Civils de Lyon, F-69677 Bron, France

b Service de génétique, Hôpital Femme Mère Enfant, Hospices Civils de Lyon, F-69677 Bron, France

c Service d'obstétrique, Hôpital Femme Mère Enfant, F-69677 Bron, France

d Université de Lyon, F-69008 Lyon, France

e Institut des Sciences Cognitives, CNRS UMR 5304, F-69675 Bron, France

${ }^{\mathrm{f}}$ Réanimation néonatale, HFME, F-69677 Bron, France

${ }^{g}$ Neuropédiatrie, CHU de Montpellier, F-34295 Montpellier, France

${ }^{\mathrm{h}}$ U1046 INSERM UMR 9214 CNRS, Université de Montpellier, France

${ }^{\mathrm{i}}$ Radiologie pédiatrique et médecine foctale, Hôpital Femme Mère Enfant, F-69677 Bron, France

Keywords:

Cognitive outcome

Corpus callosum agenesis

Population-based prospective study

\begin{abstract}
A B S T R A C T
Objectives: Neurodevelopmental outcome of apparently isolated agenesis of the corpus callosum (ACC) remains a major concern with uncertain prognosis. Despite "normal" IQ reported in a majority of patients, the rates of learning disabilities and severe outcome (ranging from $0 \%$ to $20 \%$ ) are not clearly established.

Methods: A large population-based series was investigated based on a longitudinal follow-up until school age, using Wechsler Intelligence scales at 3, 5, and 7 years.

Results: Fifty women were referred to a tertiary referral unit for an "apparently" isolated ACC confirmed by ultrasound, foetal MRI, and karyotyping or array CGH. Twelve pregnancies were terminated, one foetus died in utero, one pregnancy outcome was unknown, and 36 babies were born. Two were lost to follow-up. Thirty-four children could be classified into three groups. Group 1 comprised two children (6\%) with severe intellectual disability (one Mowat-Wilson syndrome and one ASD). Group 2 comprised 10 children (29\%) who had learning disabilities and borderline intellectual functioning (VIQ and/or PIQ
\end{abstract}

Abbreviations: ACC, Agenesis of the Corpus Callosum; MRI, Magnetic Resonance Imaging; WPPSI-III/WPPSI-IV, the Wechsler Preschool and Primary Scale of Intelligence 3rd/4th edition; WISC-IV, the Wechsler Intelligence Scale for Children 4th edition; IQ Intellectual Quotient; PIQ Performance/Visuospatial IQ; VIQ Verbal IQ; FSIQ Full Scale Intellectual Quotient; ASD, Autism Spectrum Disorder; ID, Intellectual Disability; SLD, Specific learning disability; ADHD, Attention Deficit and Hyperactivity Disorder; SLI, Specific language impairment.

* Corresponding author. Centre de référence « Déficiences Intellectuelles de causes rares », Hôpital Femme Mère Enfant, Hospices Civils de Lyon, F-69677 Bron, France.

E-mail address: vincent.desportes@chu-lyon.fr (V. des Portes). 
scores $>70$ and $<85)$; three patients had hypopituitarism with additional MRI anomalies revealed after birth. Group 3 comprised 22 children (65\%) who had both VIQ and PIQ > 85 $(-1 \mathrm{SD})$ with a normal school level. Longitudinal follow-up revealed weaker PIQ in younger children which improved with age.

Conclusion: Our data indicate that intellectual ability is normal (IQ > 85) in approximately two thirds and borderline in just over a quarter of patients. However, a low risk of severe cognitive impairment exists, and this information should be shared with couples during prenatal counselling.

\section{Introduction}

Agenesis of the corpus callosum (ACC) is the most common brain malformation detected by routine ultrasound at 22 weeks of gestational age, with a reported prevalence at birth of around 1:4000 to 1:5000..$^{1,2}$ ACC can result from vascular, toxic, and infectious insult or be associated with more than 200 different syndromes or metabolic diseases, ${ }^{3}$ most of them leading to moderate to severe neurodevelopmental disability. Surprisingly, several studies of children with isolated ACC diagnosed during pregnancy reported a favourable outcome for the majority. ${ }^{3-10}$ According to an integrative review including 132 patients from 16 studies, ${ }^{3}$ normal neurodevelopment was reported in 71\% (95\% CI: 63-78), borderline outcome or moderate disability in 14\% (95\% CI: 8.8-20.5), and severe disability in 15\% (95\% CI: 10-22.2).

Poor outcome was often related to a syndromic form of ACC which was not detected prenatally. Indeed, if the majority of syndromic ACC cases are associated with other brain malformations or congenital defects, some can be revealed by apparently isolated ACC without other malformation. New genetic techniques, such as array comparative genomic hybridization (CGH), have become available in prenatal settings, allowing detection of subtle copy number variants (CNV) in $5-7 \%$ of cases of ACC with normal karyotypes. ${ }^{11}$ Nevertheless, these techniques cannot detect discrete gene mutations involved in various monogenic disorders (e.g. Mowat-Wilson, Pitt-Hopkins, Coffin-Siris, pyruvate dehydrogenase deficiency, non-ketotic hyperglycinaemia, etc.), and such disorders are not yet screened during current prenatal diagnostic workup. For this reason, cognitive outcome of "apparently" isolated ACC remains a major concern with uncertain prognosis. The fear of not recognizing rare but severe syndromic ACC cases explains the continued high rate of pregnancy termination and heterogeneity of counselling information given to couples among prenatal diagnostic centres. ${ }^{3,12}$

Despite very informative series already reported by different teams ${ }^{3-10}$ and a recent meta-analysis, ${ }^{11}$ current knowledge on isolated ACC is still lacking due to numerous limitations: a majority of retrospective studies, small series (3-16 patients, except one with 26 patients), ${ }^{9}$ a paucity of population-based studies, a high rate of patients lost to follow-up, a lack of standardized psychometric tools, ${ }^{3}$ and a short duration of follow-up (2-4 years, except one study to 10 years). ${ }^{10}$
Additional data are mandatory ${ }^{11}$ with regards to two issues in particular that are still under debate: (i) the rate of severe outcome, ranging from $0 \%$ to $20 \%$, which may only be captured by prospective and population-based studies comprising all patients; and (ii) the rate of borderline intellectual functioning and learning disabilities among children with so called "normal development", which requires long-term follow-up until school age and standardized cognitive assessment.

In this study, we aimed to address these points by describing, for the first time, a large clinical population-based series with longitudinal follow-up, using standardized psychometric tests, of 34 children born to women referred to a tertiary referral unit due to "apparently" isolated ACC.

\section{Patients and methods}

\subsection{Population}

\subsubsection{Inclusion criteria}

All children were born to women referred due to "apparently" isolated ACC at the same centre between 2004 and 2012, and registered in a comprehensive database. All had a prenatal diagnosis of "apparently" isolated ACC (either partial or complete) on ultrasound performed at around 22 weeks or later, and MRI after 30 weeks of gestational age. All diagnoses of ACC were checked by the same ultrasound expert (LG), according to sonographic signs already described (Figs. 1 and $2 \mathrm{~A}-\mathrm{C}){ }^{13}$

Exclusion criteria included additional cerebral or extracerebral malformation, consanguinity, a family history of developmental delay (parents or siblings), a genetic defect on foetal karyotyping or array CGH (after 2013), and foetal infection, or alcohol consumption during pregnancy. Moreover, cases of corpus callosum hypoplasia were excluded (Fig. 2D).

\subsection{Follow-up protocol}

An 11-year prospective study was performed from 2004 to 2015 with a standardized protocol as follows. Clinical visits with a child neurologist (VDP and DV) for newborns and at 6 , 12 , and 24 months were conducted to assess early neurodevelopment. In addition to an annual medical visit by a child neurologist, standardized Wechsler Intelligence Scales were also performed at three, five and seven years. The WPPSI-III or 


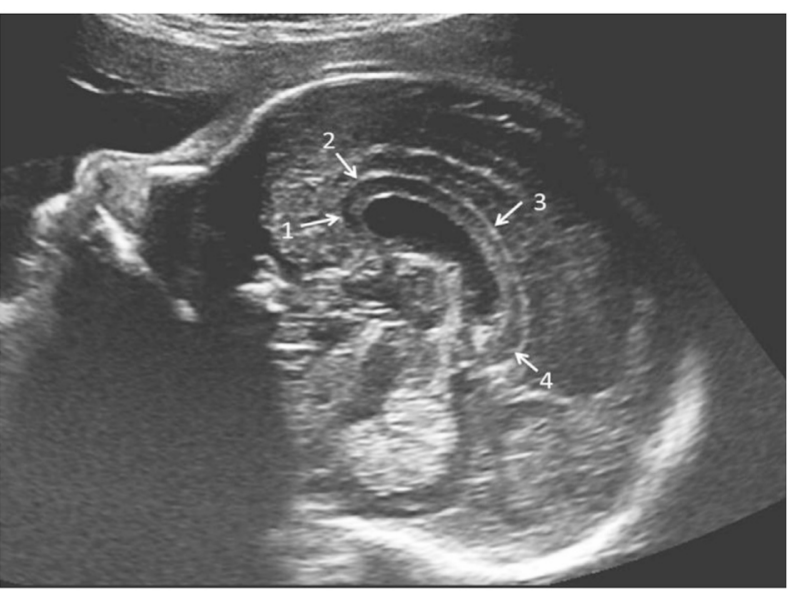

Fig. 1 - Sonographic midsagittal image at 27 weeks showing the normal anatomy of the corpus callosum, which includes the following anatomical parts: rostum (1), genu (2), body (3), and splenium (4).

WPPSI-IV tests were used at three and five years, and WISC-IV test was used at seven years. ${ }^{14}$ For each child, all IQ tests were performed by the same neuropsychologists (either JVD or EP), and performance related to school curriculum, learning disabilities, and participation in a rehabilitation programme were also carefully recorded. Brain MRI was also systematically proposed for every newborn. The duration of follow-up was variable, depending on age. The youngest children born between 2010 and 2012 had only one WPPSI-III assessment at three years old.

\subsection{Data analysis and ethical issues}

Statistical analysis was performed using R software (http:// www.r-project.org). Discrete variables were expressed as numbers of cases and percentages, and were analysed using a Fisher's exact test. For continuous variables, results were expressed as mean and standard deviation. Regarding the IQ data, the latest assessment for each patient was used, as the IQ test becomes more reliable and precise with age. The normality of the data distribution was first checked using the Shapiro and Wilk normality test on both PIQ and VIQ. IQ data were then analysed using a repeated measures ANOVA with one group factor (partial and complete ACC). Significance was considered at $\mathrm{p}<0.05$. All IQ data, obtained at the age of 3,5 and 7 years, were compared in order to estimate the effect of age on the psychometric profile. IQ data were then analysed within each group of age $(3,5$, and 7 years) using a repeated measures ANOVA with one within-group factor (PIQ/VIQ). A between group analysis was also performed. A significance level of $p<0.05$ was chosen. Post-hoc analysis was performed using the Scheffé test. We also performed a linear regression analysis on IQ scores with age within Group 2, 3A and 3B, respectively. This longitudinal follow-up was performed within the frame of routine clinical visits and no further written consent was required from parents. Neither photographs nor blood samples were specifically required for the study.

\section{Results}

Over a nine-year period (2004-2012), "apparently isolated" ACC was detected in 50 women (Fig. 3). Twelve pregnancies were terminated, one foetus died in utero, one pregnancy outcome was unknown, and 36 babies were born. Two were lost to follow-up because of parents' refusal to participate in the study. As far as we know, no neurodevelopmental delay was detected at the age of three years.

Thirty-four neonates were included in the prospective study. Twenty-two (65\%) were boys (sex ratio: 2; significantly different from that in the general population in France of 1.05; $p=0.04)$. Twenty-six children (76\%) had a complete ACC and eight (24\%) a partial ACC. Ultrasound was complemented by foetal MRI for 33/34 foetuses (97\%). Postnatal brain MRI was performed in $26 / 34$ children (76\%). For the eight remaining patients, MRI was refused by parents or could not be technically performed (due to excessive movement by the baby). All were born at full term apart from two (one at 33 weeks of gestation due to gravidic hypertension and one at 36 weeks due to hypotrophy). Five were delivered by Caesarean section with good neonatal adaptation. Additional congenital defects were discovered at birth in five patients: one cleft palate, one hypospadias, one micropenis, one postaxial polydactyly in a foot, and one polymalformation including facial dysmorphism, cardiac defect, and Hirschprung disease leading to the diagnosis of Mowat-Wilson syndrome.

The 34 patients were classified into three groups according to their cognitive abilities.

Group 1 included two children (6\%) with ID, who were not able to perform standardized IQ tests. The first was the girl with Mowat-Wilson syndrome (ZEB2 gene mutation). She had epilepsy and severe ID, and required assistance to walk and did not talk. Postnatal MRI confirmed isolated complete ACC without further brain anomaly. The other child was a threeyear-old boy with partial ACC who had global developmental delay and ASD. He walked alone at 34 months and did not have any expressive language at the time. Postnatal MRI confirmed isolated partial ACC; CGH was normal.

The 32 remaining patients were classified according to their latest IQ assessment. All had one to three IQ assessments (Table 1). Since 18 of the 52 Wechsler Scales performed (35\%) showed a difference of 15 points or more between VIQ and PIQ scores, calculation of the FSIQ was not relevant and not used in this study.

Group 2 included ten children (29\%) who had borderline intellectual functioning (VIQ and/or PIQ scores <85; -1 SD) without intellectual disability (VIQ and/or PIQ scores $>70 ;-2$ $\mathrm{SD})$. Among them, three patients had partial or complete panhypopituitarism requiring hormone supplementation. Postnatal brain MRI was available in eight of the 10 patients. Except for the patients with hypopituitarism (Fig. 4), no additional brain anomalies were revealed in the five other patients. Six patients were older than five years; all required speech therapy and human support at school; three were provided with a special school curriculum; and four required sensorimotor therapy. All had one or more diagnoses corresponding to an SLD: three dyslexia, two ADHD, four dyspraxia, and four with SLI. 


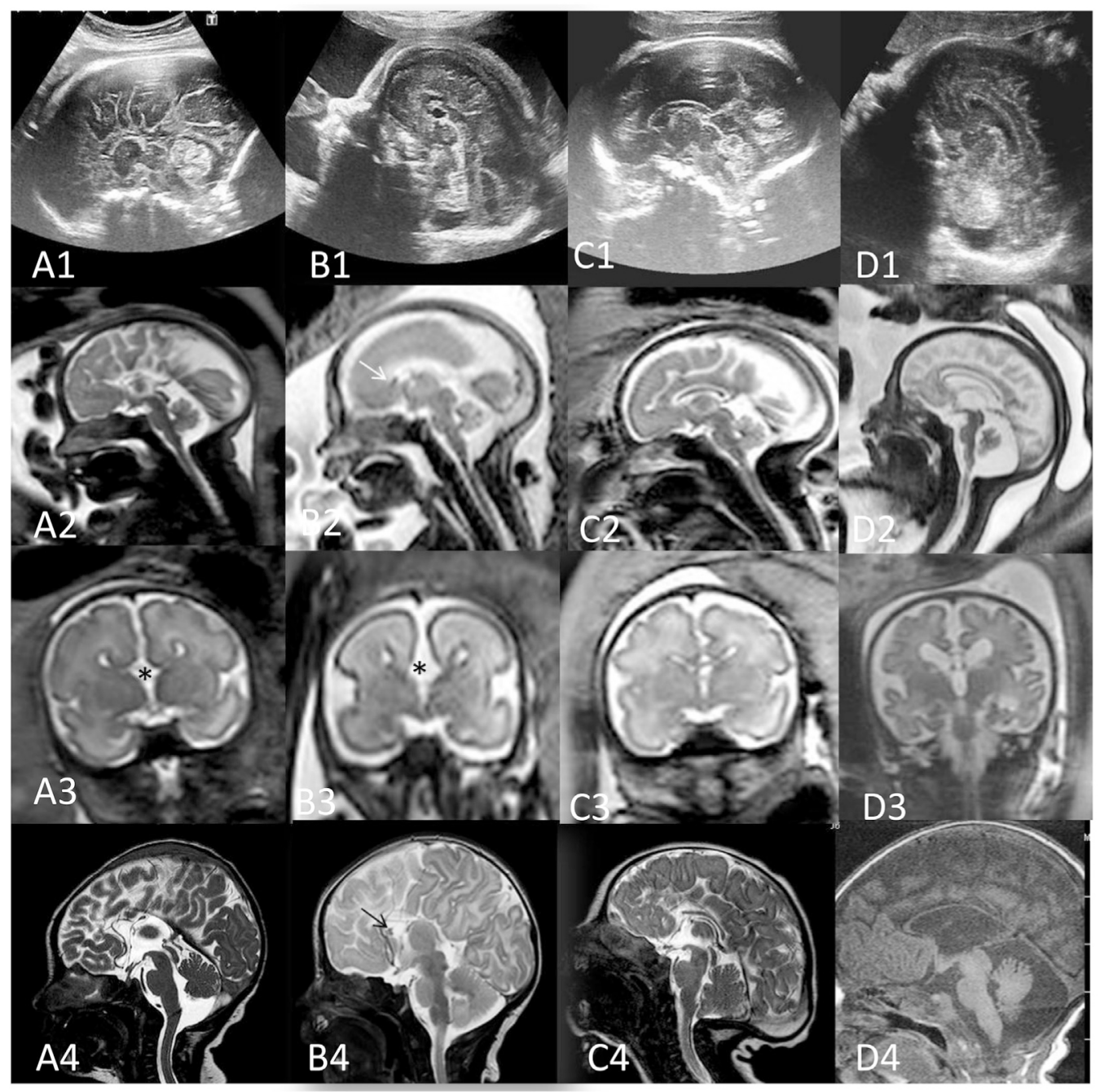

Fig. 2 - Prenatal sonographic (midsagittal) and foetal (midsagittal, coronal) post-natal (midsagittal) MR images of different types of callosal dysgenesis including the following entities: (A) complete agenesis (*) with complete absence of the corpus callosum; (B) extensive partial agenesis (*) showing the presence of the genu (arrow), the most primitive part of the corpus callosum; (C) limited partial agenesis showing the presence of the entire body of the corpus callosum, but partial absence of both splenium and genu without any identification of the rostrum, the last part to form in embryology; and (D) hypoplasia of the corpus callosum showing abnormal thinness of the corpus callosum despite normal anatomy. Note that indirect findings (such as radiated pattern of sulci on the internal border of cerebral hemispheres, frontal horn deformation with coma shape appearance, absence of the cavum septum pellucidi, and ascent of the third ventricle) are present during complete agenesis $(A)$ and partially present in extensive partial agenesis (with the presence of a small cavum septum pellucidi and moderate ascent of the third ventricle) (B). In contrast, these indirect findings are very subtle in limited partial agenesis (with almost no frontal horn deformation, normal cavum septum pellucidi, and normal third ventricle location) (C), and are completely absent in callosal hypoplasia showing a normal shape of the frontal horn (D).

Group 3 included twenty-two children (65\%) who had IQ within the strict normal range $(>85,-1 \mathrm{SD})$ for both verbal and visuospatial skills (Table 1). Six (18\%) children were included in Group 3A based on the fact that they had either a single mild SLD (four had ADHD and three dyslexia), and/or rehabilitation intervention (five had speech therapy, two had sensorimotor therapy, and three had human support at school); all achieved the level stipulated by the standard school curriculum. Sixteen $(47 \%)$ children were classified as Group 3B since they had no learning complaint; the sex ratio within this group was high (12 boys out of 16 children; sex ratio: 3 ). One child of group 3B had benign epilepsy with centrotemporal spikes without treatment.

The association between hypopituitarism and moderate learning disabilities was significant (Fisher exact, $p=0.02$; based on a comparison between Groups 2 and 3). Learning disability in Group 2 was more severe than in Group 3A; when comparing children aged five years or older in both groups (six patients in each group), five of Group 2 and none of Group 3A had multiple SLD (Fisher exact, $p=0.015$ ), and the requirement for human support or special schooling was significantly greater in Group 2 compared to Group 3A (Fisher exact, $p=0.012$ ). 


\begin{tabular}{lll} 
& 36 newborn (72\%) & 12 abortions (24 \%) \\
\hline 2 lost (refusal) & 34 follow-up & 1 lost prenatally
\end{tabular}

2 severe ID

1 Mowat-Wilson

1 unknown syndrome

\section{Group 1}

$6 \%(2 / 34)$

Moderate/severe

Developmental Delay/ID
10 multiple learning

disabilities

(without ID)

Group 2

$29 \%(10 / 34)$

multiple learning disab.

and $70<\mid Q<85$
$16 \mathrm{IQ}>85$

and good

learning skills

$16 / 34(47 \%)$

Group 3B

Fig. 3 - Flowchart of the population-based survey of 50 women referred due to an "apparently" isolated ACC, and cognitive outcome of 34 children.

Table 1 - VIQ and PIQ assessment of 32 children using the Wechsler scale appropriate for age. Seventeen/32 patients were tested at the age of three (mean age: 3.3 years), 20 of the 25 patients older than five years were tested at the age of five (mean age: 5.1 years) and 15 of the 15 patients older than seven years were tested at the age of seven (mean age: 7.9 years). M: male; F: female.

\begin{tabular}{|c|c|c|c|c|c|c|c|c|c|}
\hline \multirow[t]{2}{*}{ Patient } & \multirow[t]{2}{*}{ Group } & \multirow[t]{2}{*}{ Sex } & \multirow[t]{2}{*}{ Type of ACC } & \multicolumn{2}{|c|}{3 years: WPPSI-III } & \multicolumn{2}{|c|}{5 years: WPPSI-III } & \multicolumn{2}{|c|}{ >7 years: WISC-IV } \\
\hline & & & & Verbal & Performance & Verbal & Performance & Verbal & Performance \\
\hline 1 & $3 B$ & F & complete & & & 120 & 85 & & \\
\hline 2 & $3 B$ & M & complete & & & not available & 109 & 101 & 135 \\
\hline 3 & $3 B$ & $\mathrm{~F}$ & complete & 112 & 95 & 108 & 104 & & \\
\hline 4 & $3 B$ & $\mathrm{~F}$ & complete & 112 & 88 & 107 & 125 & & \\
\hline 5 & 3B & $\mathrm{F}$ & complete & & & 91 & 90 & & \\
\hline 6 & 3B & M & complete & 88 & 92 & & & 112 & 111 \\
\hline 7 & 3B & M & complete & 99 & 103 & & & & \\
\hline 8 & $3 B$ & M & complete & & & 102 & 113 & 103 & 111 \\
\hline 9 & $3 B$ & M & complete & & & 91 & 87 & & \\
\hline 10 & $3 B$ & M & complete & & & 98 & 107 & & \\
\hline 11 & $3 B$ & M & partial & 133 & 106 & & & & \\
\hline 12 & $3 B$ & $\mathrm{M}$ & partial & & & 130 & 119 & 135 & 114 \\
\hline 13 & $3 B$ & M & partial & 133 & 112 & & & 135 & 121 \\
\hline 14 & $3 B$ & M & partial & & & 111 & 111 & & \\
\hline 15 & $3 B$ & M & partial & & & 102 & 98 & 110 & 116 \\
\hline 16 & $3 B$ & M & complete & 120 & 126 & & & & \\
\hline 17 & $3 \mathrm{~A}$ & $\mathrm{~F}$ & complete & 102 & 85 & 93 & 92 & 98 & 90 \\
\hline 18 & $3 \mathrm{~A}$ & M & complete & 109 & 103 & 95 & 107 & 96 & 107 \\
\hline 19 & $3 \mathrm{~A}$ & $\mathrm{~F}$ & complete & 102 & 76 & 93 & 105 & & \\
\hline 20 & $3 \mathrm{~A}$ & M & complete & & & 111 & 134 & 135 & 126 \\
\hline 21 & $3 \mathrm{~A}$ & M & complete & & & 102 & 119 & 110 & 128 \\
\hline 22 & $3 \mathrm{~A}$ & $F$ & partial & 96 & 57 & 102 & 87 & & \\
\hline 23 & 2 & M & complete & 93 & 82 & & & & \\
\hline 24 & 2 & M & complete & 78 & 85 & & & & \\
\hline 25 & 2 & $\mathrm{~F}$ & complete & & & 84 & 77 & & \\
\hline 26 & 2 & $\mathrm{~F}$ & complete & & & & & 84 & 73 \\
\hline 27 & 2 & M & complete & 71 & 54 & 83 & 92 & 82 & 82 \\
\hline 28 & 2 & M & complete & & & & & 90 & 73 \\
\hline 29 & 2 & $\mathrm{~F}$ & complete & & & & & 82 & 99 \\
\hline 30 & 2 & M & partial & 81 & 82 & & & & \\
\hline 31 & 2 & $F$ & complete & 82 & 75 & 83 & 90 & 69 & 75 \\
\hline 32 & 2 & $F$ & complete & 64 & 75 & & & & \\
\hline
\end{tabular}



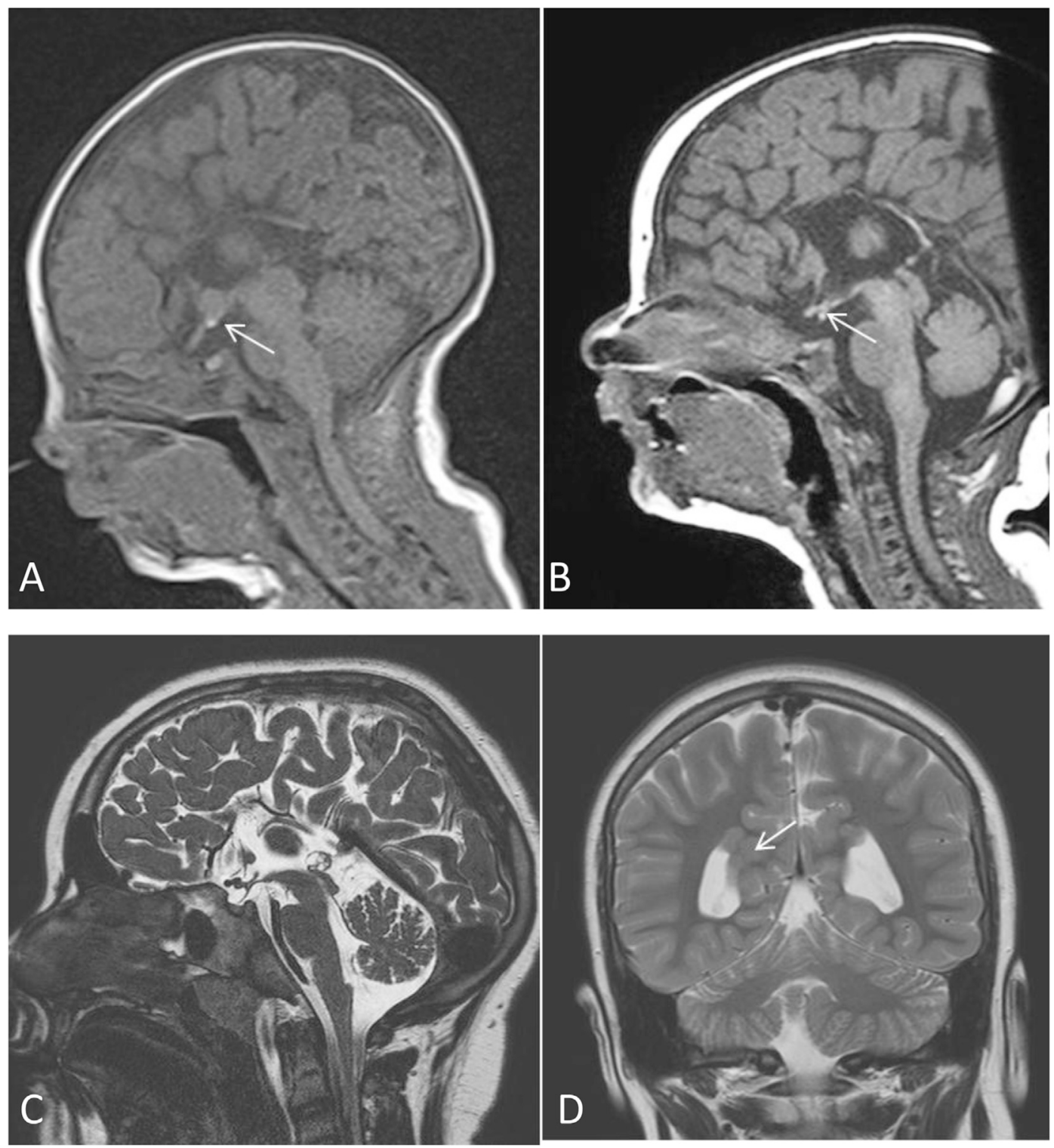

Fig. 4 - Midsagittal T1-weighted neonatal MR image showing complete absence of the corpus callosum associated with both absence of pituitary stalk and ectopic neuro-hypophysis (arrow) in Case 27 (micropenis and hypoglycaemia at birth) (A) and Case 32 (frank axial hypotonia at birth, which improved after thyroid hormone intake) (B). In Case 31 (an overweight patient with motor delay and thyroid and growth hormone deficits), midsagittal and coronal T2-weighted MR images from an examination performed at nine years revealed complete absence of the corpus callosum (C), associated with subependymal heterotopia protruding into the medial borders of the occipital horns (arrow) (D), more marked on the right side. Note that these heterotopia were suspected on the initial neonatal MR examination, but were barely visible, as also noted retrospectively on foetal MRI.

Both VIQ and PIQ scores followed a normal distribution (Fig. 5). We then compared 25 children with complete ACC and seven with partial ACC for both PIQ (mean PIQ: 99 and 105, respectively) and VIQ (mean VIQ: 98 and 112, respectively), but the difference was not statistically significant. A lack of data hampered any attempt to draw individual cognitive trajectories. Thus, all IQ tests were pooled according to the age of assessment, at 3, 5 or 7 years, in order to have a better estimate of the cognitive profile evolution with age. There was a significant effect of age on PIQ $(p=0.016)$, but not on VIQ. More precisely, post-hoc analysis revealed that three-year-old children had a significantly lower PIQ compared to five-yearolds $(p=0.046)$ and seven-year-olds $(p=0.024)$, respectively. Interestingly, visuospatial skills were weaker than verbal abilities at the age of three years $(p=0.008)$, but this difference did not persist at five years $(p=0.47)$ or seven years $(p=0.75)$ (Fig. 6). A developmental trajectory of PIQ scores was performed for each subgroup (2, 3A, and 3B). No significant effect of age was observed in Group 2 or 3B, since PIQ scores were relatively stable above 100 in Group 3B, and around 75 to 80 in Group 2. However, a significant effect of age was found in Group 3A; the older the child, the higher the PIQ (Fig. 7). 
A

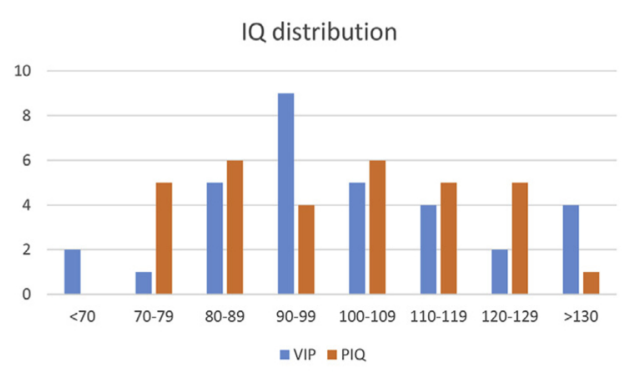

B

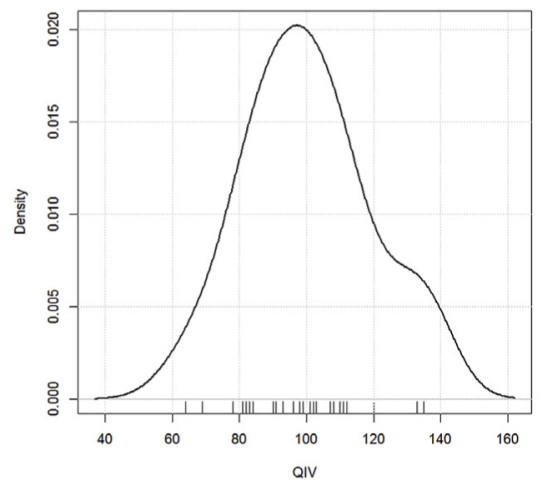

C

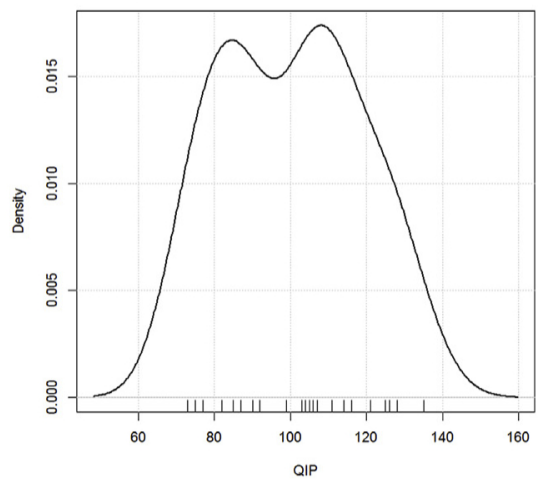

Fig. 5 - (A) Normal distribution of VIQ (mean VIQ: 100.5; SD: 18.6) and PIQ (mean PIQ: 100.2; SD: 18.3) scores, based on data of the latest assessment performed for each patient. $(B, C)$ Density estimates of VIQ distribution and PIQ distribution, respectively. Shapiro-Wilk normality test: $\mathrm{W}=0.97, p=0.37$ for VIQ; $\mathrm{W}=0.95, p=0.14$ for PIQ.

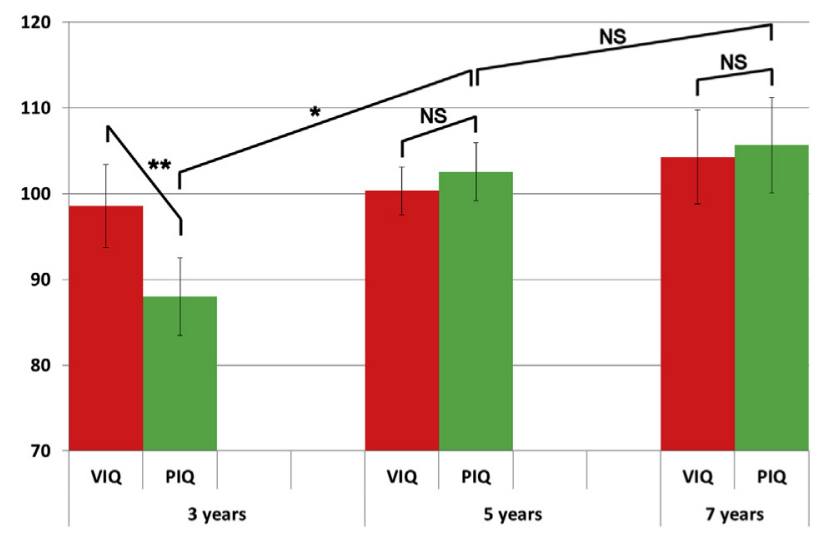

Fig. 6 - VIQ and PIQ in 32 children with ACC at the age of three, five and seven years. Visuospatial skills were weaker than verbal abilities at the age of three years $(p=0.008)$, but not at five $(p=0.47)$ and seven years $(p=0.75)$.

\section{Discussion}

This study describes the largest population-based series of apparently isolated ACC which was carefully assessed using a standardized cognitive longitudinal follow-up until three to seven years old.

4.1. Inclusion criteria and outcome measures used in this series and previously reported series

At a first glance, cognitive outcome of children in our series did not differ significantly from other studies; $65 \%$ had an IQ > 85, compared to $71 \%$ of "normal outcome" in two different meta-analyses. ${ }^{3-11}$ Nevertheless, comparing outcome data between different series requires careful consideration of any differences in inclusion/exclusion criteria. For instance, we did not take into account the degree of ventricle dilation, in

\section{Group 3A}

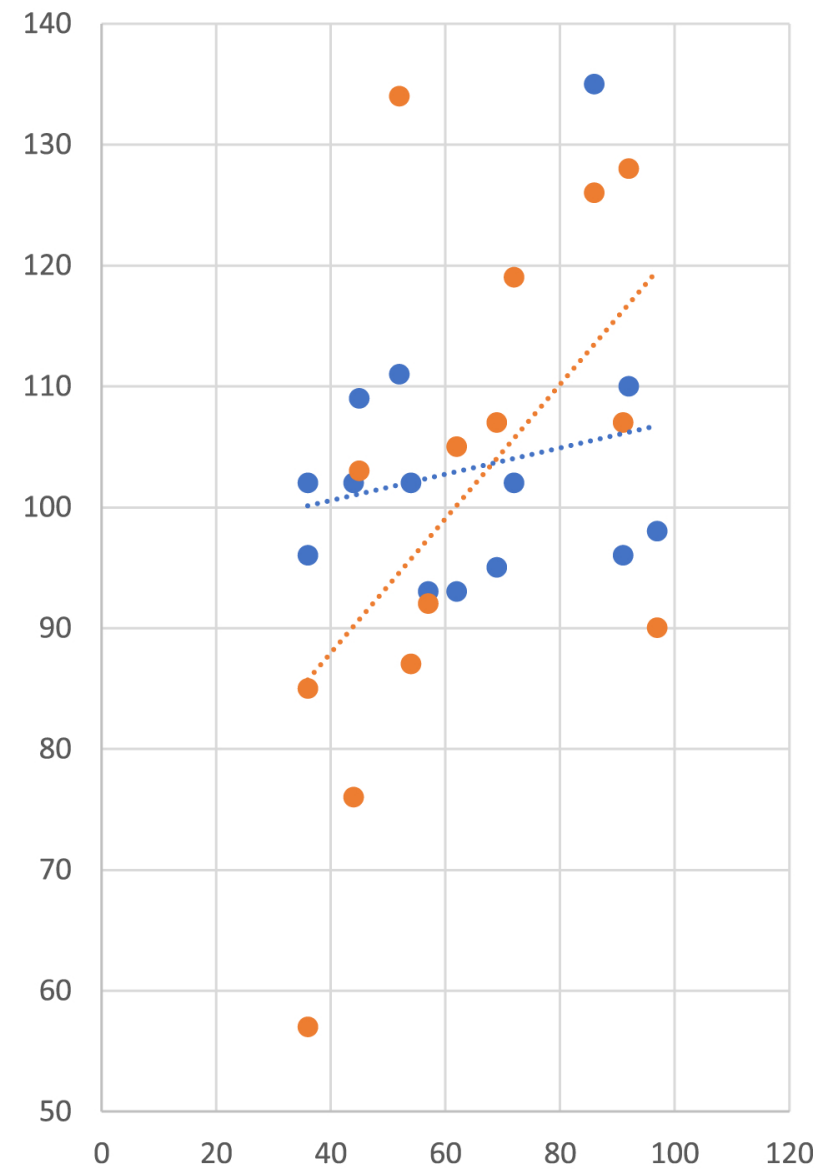

Fig. 7 - Linear regression analysis of VIQ (blue) and PIQ (orange) with age within Group 3A. A significant effect of age was found for PIQ $\left(r^{2}=0.3, p=0.045\right)$. (For interpretation of the references to colour in this figure legend, the reader is referred to the web version of this article.) 
contrast to two other series, ${ }^{7-9}$ in which patients with ventricles $>15 \mathrm{~mm}$ were excluded (a putative factor for poor outcome) ${ }^{15}$ Conversely, we excluded CC hypoplasia, which were included in these series. ${ }^{7-9}$ The rate of complete/partial ACC was also fairly variable in different studies, from $100 \%$ complete $\mathrm{ACC}^{6,8,15}$ to $100 \%$ partial ACC. ${ }^{16}$ Nevertheless, the degree of ACC did not significantly influence outcome between six children with partial ACC and 11 with complete ACC. ${ }^{4}$ In our series, we could not determine any difference, possibly due to the small number of patients with partial ACC.

More importantly, to accurately address neurodevelopmental outcome of children with apparently isolated ACC diagnosed prenatally, it is mandatory to analyse all cases, even those who are not able to participate in cognitive assessment and those with associated CNS anomalies revealed postnatally. Unfortunately, in a systematic review of cognitive profiles of ACC patients, ${ }^{17}$ individuals with severe impairment were excluded. Also, in the recent meta-analysis, ${ }^{11}$ children with associated CNS anomalies discovered after birth were ruled out, thus minimizing the rate of severe cognitive impairment.

As already noticed, ${ }^{3}$ another major issue to consider before comparing published studies is the lack of consensus on the meaning of "normal outcome" and "mild, moderate and severe disability". In the first study, ${ }^{7}$ patients were classified into three groups. In the first group, "normal outcome" (11/20; 55\% of patients), children were classified with no cognitive or motor impairment. Nevertheless, among the 11 patients with "normal outcome" (according to table $\mathrm{S}^{7}$ ), one patient had a VIQ of 83 and required special education, psychotherapy, and speech therapy. In our study, the patient would have been classified in Group 2, with "moderate disability". Moreover, seven children did not have any IQ testing, and nothing was mentioned about school achievement, thus mild cognitive dissociation and/or specific learning difficulties may have been overlooked (such as in Group 3A of our series). Finally, 10 of 11 patients classified as "normal outcome"" (50\% of the series) would correspond to our entire Group 3 (3A and 3B; 65\% of our patients). In the second group, "moderate disability" (5/ $20 ; 25 \%)$, patients had moderate early hypotonia and/or subtle cognitive disorder such as dyslexia, visuospatial attention deficit, or learning disabilities, with or without a need for specific treatment, but without severe motor impairment. The cognitive profile and educational needs of the five patients described correspond to patients of our Group 2. Lastly, the "severe disability" group (4/20; $20 \%)$ included cerebral palsy or intellectual disability (IQ $<70$ ), corresponding to our Group 1 (2/34; $6 \%$ in our series).

In the second study, ${ }^{9}$ the outcome measure was the Child Development Inventory (CDI), which is a parental questionnaire describing the child's behaviour, allowing for calculation of a developmental score (DQ-CDI) with relatively good correlation with the IQ WPPSI test $(r=0.85)$. Children assessed were followed to a median age of four years (two and a half to six). Authors considered developmental delay as DQ-CDI $<79$, with borderline disability $(70<\mathrm{DQ}-\mathrm{CDI}<79)$ and intellectual disability (DQ-CDI < 70). They found only two patients $(8 \%)$ with borderline disability (our Group 2), possibly due to the fact that children were too young to reveal learning disabilities. They also found five with intellectual disability (19\%), which corresponds to the rate of $20 \%$ described in the first study, ${ }^{7}$ much more than in Group 1 of our series.

In the third study, ${ }^{10} 12$ patients were followed to 10 years old, with IQ tests (WISC-III). Since VIQ and PIQ tests were available, patients could be easily classified in Groups 2 or 3, according to the criteria of our study. Moreover, in Group 3, one patient had school adjustment and rehabilitation, and was classified in Group 3A.

In Table 2, the outcomes described in ten studies are summarised and classified into four groups. ${ }^{4-10,15,16}$ Some data were "revisited" according to the criteria proposed in our series., 7,10 Due to discrepancies between study designs (outcome measures, duration of follow-up, retrospective/ prospective series), no meaningful conclusion can be drawn from pooled data, as already noted in meta-analyses and systematic reviews. . $^{3,11,17}$

\subsection{Frequency of severe disability}

Unexpected severe developmental delay is still a major issue in apparently isolated ACC and this threat strongly influences couples' decision to terminate pregnancy. ${ }^{3,12}$ The range of severe disability ( $6 \%$ in this study) varies widely according to the series (Table 2); from $0 \%{ }^{4,8,10}$ to around $20 \%$. $^{6,7,9}$ Two major causes are responsible for severe disability: first, associated brain malformation discovered after birth, and second, rare syndromic ACC not detectable by current prenatal genetic screening.

During prenatal medical workup, the extent of necessary systematic MRI, in addition to ultrasound, is still under debate. ${ }^{4,6,8,11,13,16,18}$ Prenatal MRI was not performed by Cignini et al. (2010) who compared results between prenatal ultrasound and postnatal MRI, and did not find any additional malformation. Authors argued that the risk of false "apparently" isolated ACC and related poor outcome is reduced in prenatal diagnostic centres in which there are expert neurosonographers (Cignini et al., 2010). In contrast, several reports of series have described additional brain anomalies on postnatal MRI, not detected by foetal ultrasound. For instance, Volpe et al. (2006) identified two malformations which were not visible on ultrasound (micropolygyria and nodular heterotopias). Also, Pisani et al. (2006) reported that among nine patients, one associated malformation was detected on foetal ultrasound but two others were overlooked and diagnosed only on postnatal MRI. Indeed, additional anomalies not detected on prenatal ultrasound were diagnosed on foetal MRI in $8 \%$ and $12 \%$ of complete and partial ACC, respectively, in the recent meta-analysis of D'Antonio et al. (2016). Interestingly, in the series of Moutard et al. (2003), all patients had isolated ACC which was confirmed on both ultrasound and foetal MRI, and no additional brain anomaly was detected postnatally, possibly contributing to the absence of poor outcome in this series. Taking into account all these data, coupling foetal MRI and ultrasound increases the chance of detecting associated brain malformations, thus, foetal MRI would appear to be worthwhile during prenatal workup. However, the yield of MRI depends on gestational age; resonance imaging before 25 weeks of gestation may be misleading (Malinger et al., 2004; Cignini et al., 2010) and this examination should be performed at around 30 weeks of 
Table 2 - Summary of cognitive outcomes of apparently isolated ACC diagnosed in prenatal settings, extracted from 10 series. In order to homogenize the meaning of

"normal outcome" and "mild, moderate or severe disability", published data were carefully checked and classified according to the four groups of our study, as much as

possible, depending on available data. Volpe et al. included two cases with very short follow-up (16 and 19 months, respectively). For Pisani et al. (2006), one of the nine

patients who had associated brain malformation diagnosed prenatally was excluded in the Table. CDI: Child Development Inventory.

\begin{tabular}{|c|c|c|c|c|c|c|c|c|c|c|c|c|c|c|}
\hline \multirow[t]{2}{*}{ Study } & \multirow{2}{*}{$\begin{array}{l}\text { Type of } \\
\text { study }\end{array}$} & \multirow{2}{*}{$\begin{array}{c}\text { Number } \\
\text { of } \\
\text { newborns }\end{array}$} & \multirow{2}{*}{$\begin{array}{l}\text { CACC vs } \\
\text { PACC }\end{array}$} & \multicolumn{2}{|c|}{ Imaging } & \multirow{2}{*}{$\begin{array}{c}\text { Postnatal } \\
\text { associated } \\
\text { ACC }\end{array}$} & \multirow{2}{*}{$\begin{array}{c}\text { Duration } \\
\text { of follow- } \\
\text { up }\end{array}$} & \multirow{2}{*}{$\begin{array}{l}\text { Lost to } \\
\text { follow- } \\
\text { up }\end{array}$} & \multirow{2}{*}{$\begin{array}{c}\text { Number of } \\
\text { assessed } \\
\text { patients }\end{array}$} & \multirow{2}{*}{$\begin{array}{l}\text { Cognitive } \\
\text { assessment }\end{array}$} & \multicolumn{4}{|c|}{ Cognitive Outcome } \\
\hline & & & & $\begin{array}{l}\text { Foetal } \\
\text { MRI }\end{array}$ & $\begin{array}{l}\text { Postnatal } \\
\text { MRI }\end{array}$ & & & & & & $\begin{array}{l}\text { Group } 1 \\
\text { "Severe" } \\
\text { disability }\end{array}$ & $\begin{array}{l}\text { Group } 2 \\
\text { "Moderate" } \\
\text { learning } \\
\text { disability }\end{array}$ & $\begin{array}{l}\text { Group 3A } \\
\text { "Mild" } \\
\text { learning } \\
\text { disability }\end{array}$ & $\begin{array}{l}\text { Group } \\
3 \mathrm{~B} \\
\text { Normal }\end{array}$ \\
\hline Moutard & prospective & 17 & $11 / 6$ & 17 & 17 & 0 & $4 y(2-8 y)$ & 1 at $2 y$ & 16 at $2 y$ & Brunet-Lezine $\mathrm{R}$ & 0 & $1(6 \%)$ & $2(13 \%)$ & $13(81 \%)$ \\
\hline et al. & & & & & & & & 8 at $4 y$ & 9 at $4 y$ & WPPSI-R & 0 & $2(22 \%)$ & $1(11 \%)$ & $6(67 \%)$ \\
\hline (2003) & & & & & & & & 10 at $6 y$ & 7 at $6 y$ & WPPSI-R & 0 & $3(43 \%)$ & NA & $4(57 \%)$ \\
\hline $\begin{array}{l}\text { Volpe } \\
\text { et al. } \\
\text { (2006) }\end{array}$ & retrospective & 9 & $0 / 9$ & 5 & 9 & 1 & $\begin{array}{l}\text { Median: 3y } \\
(1-6 y)\end{array}$ & 1 & 8 & $\begin{array}{l}\text { no standardized } \\
\text { test }\end{array}$ & $2(25 \%)$ & 0 & $\mathrm{NA}$ & $6(75 \%)$ \\
\hline $\begin{array}{l}\text { Ramelli } \\
\text { et al. } \\
\text { (2006) }\end{array}$ & retrospective & 3 & $3 / 0$ & US only & 3 & 0 & 2, 2 and $10 y$ & $\mathrm{NA}$ & 3 & $\begin{array}{l}2 \text { Griffith, } 1 \\
\text { Weschsler }\end{array}$ & 0 & 0 & 0 & 3 \\
\hline $\begin{array}{l}\text { Pisani } \\
\text { et al. } \\
\text { (2006) }\end{array}$ & retrospective & $8(9-1)$ & $8 / 0$ & 1 & 8 & 2 & $2-16 y$ & 0 & 8 & $\begin{array}{l}3 \text { Griffith, } 6 \\
\text { Weschsler }\end{array}$ & $2(25 \%)$ & 0 & NA & 6 \\
\hline $\begin{array}{l}\text { Fratelli } \\
\text { et al. } \\
(2007)\end{array}$ & retrospective & 11 & $11 / 0$ & $\mathrm{NA}$ & 11 & 0 & $\begin{array}{l}\text { Median: } 3 y \\
(1-5 y)\end{array}$ & $4(36 \%)$ & 7 & $\begin{array}{l}\text { structured } \\
\text { questionnaire } \\
\text { (unpublished) }\end{array}$ & 1 & 3 & 0 & $3(43 \%)$ \\
\hline $\begin{array}{l}\text { Cignini } \\
\text { et al. } \\
(2010)\end{array}$ & prospective & 13 & $13 / 0$ & US only & 13 & 0 & $4 y$ & 0 & NA & $\begin{array}{l}\text { Binet-Simon } \\
\text { Scale Revised }\end{array}$ & 0 & 1 & NA & $12(92.3 \%)$ \\
\hline $\begin{array}{l}\text { Chadie } \\
\text { et al. } \\
(2008)\end{array}$ & retrospective & 20 & $11 / 2$ & 16 & 13 & 4 & $6 y(3-16 y)$ & 0 & 11 & $\begin{array}{l}\text { Brunet-Lézine } \\
\text { and Wechsler }\end{array}$ & $4(20 \%)$ & $5+1(30 \%)$ & no data & $\begin{array}{l}11-1=10 \\
(50 \%)\end{array}$ \\
\hline $\begin{array}{l}\text { Mangione } \\
\text { et al. } \\
\text { (2011) }\end{array}$ & prospective & 27 & $\begin{array}{l}18 / 6+3 \\
\text { hypoplasia }\end{array}$ & 27 & US only & 4 & $\begin{array}{l}\text { Median: } 4 y \\
(2.5-6 y)\end{array}$ & 1 & 22 & CDI & $5(19 \%)$ & $2(8 \%)$ & no data & $19(73 \%)$ \\
\hline $\begin{array}{l}\text { Moutard } \\
\text { et al. } \\
(2012)\end{array}$ & prospective & 12 & $7 / 5$ & 12 & 12 & 0 & $10 \mathrm{y}$ & 5 & 12 & WISC-III & 0 & $6(50 \%)$ & $1(8 \%)$ & $5(42 \%)$ \\
\hline This study & prospective & 34 & $26 / 8$ & 33 & 24 & 2 & $3-7 y$ & 0 & 32 & $\begin{array}{l}\text { Weschsler } \\
\text { scales }\end{array}$ & $2(6 \%)$ & $10(29 \%)$ & $6(18 \%)$ & $16(47 \%)$ \\
\hline
\end{tabular}


gestation (Guibaud, 2009). In many countries, termination of pregnancy is allowed only until 23 weeks of gestation, thus leading to a decision based only on ultrasound. All women should be referred to a dedicated neurosonographer to check the corpus callosum and other brain structures (Cignini et al., 2010), particularly when foetal MRI is not available.

Nevertheless, despite careful prenatal brain examination using ultrasound and MRI, some associated brain malformations are revealed only after birth. For instance, in a published series ${ }^{7}$ brain abnormalities (cisterna magna enlargement, cortical atrophy and nodular heterotopias) were disclosed in four patients who had foetal MRI. One patient had a good outcome and the three others a severe outcome. In the recent meta-analysis, ${ }^{11}$ additional brain anomalies were detected after birth in $5 \%$ and $14 \%$ of complete and partial ACC, respectively. In our series, foetal MRI was available for $97 \%$ of foetuses and postnatal MRI for $71 \%$ of children. Interestingly, postnatal MRI revealed additional anomalies in the three patients with pan-hypopituitarism (Fig. 4). No further brain malformations were revealed in the 21 other patients.

Monogenic disorders associated with isolated ACC (e.g. nonketotic hyperglycinaemia ${ }^{9}$ or Mowat-Wilson in our series) cannot be detected based on current prenatal workup (ultrasound, MRI and array CGH). The next challenge will be to implement NGS (new generation sequencing) techniques in prenatal settings, to screen for numerous genes involved in syndromic ACC.

\subsection{Cognitive profiles and developmental trajectories of patients without intellectual disability}

In the only study in which all patients were assessed with Wechsler scales, ${ }^{10}$ the distribution of IQ did not follow a normal distribution and revealed two groups: one with normal IQ and one with moderate disability. In contrast, both VIQ and PIQ scores followed a normal distribution in our series and did not indicate two such groups. Nevertheless, in our series, learning disabilities in Group 2 were more severe than in Group 3A, when comparing children aged five years or older, with more multiple SLD and a greater need for human or specialised support. Interestingly, the three patients with hypopituitarism were in Group 2, suggesting syndromic forms of ACC.

Longitudinal follow-up reveals interesting insights concerning the prognostic value of transient visuomotor delay. In our series, three-year-old children with ACC had a significantly lower PIQ compared to five and seven-year-olds. More specifically, a significant effect of age was found in Group 3A regarding visuospatial skills; the older the child, the higher the PIQ. In the same way, visuospatial skills were weaker than verbal abilities at the age of three years, but this difference did not persist at five or seven years (Fig. 6). In a series already cited, ${ }^{7}$ among patients with good cognitive outcome, five had transient developmental delay, hypotonia, mild speech delay, and "fine motricity problems". The lack of standardized psychometric tools in other studies hampered any detailed cognitive analysis. ${ }^{7,9}$ In the only study with IQ data available, ${ }^{10}$ there was no significant difference between VIQ and PIQ at 10 years. Nevertheless, weak visuospatial skills were reported, with poor results for puzzles and coding, compared to typical children with full IQ in the same range. ${ }^{4}$ Half of the patients, who were 10 years old, had borderline intellectual functioning, ${ }^{4}$ compared to $29 \%$ in our study. However, our patients were younger, and it was not possible to ascertain whether some of them would also have lower IQ scores at ten. Nonetheless, comparing IQ scores at six and ten years revealed a trend in improvement. ${ }^{4}$

\section{Conclusion}

In this large population-based longitudinal series, two thirds of the children had an IQ in the strict normal range (>85) and just over quarter had borderline intellectual functioning with learning disabilities. Hypopituitarism and additional MRI anomalies were revealed after birth in three patients with borderline intellectual functioning. Longitudinal follow-up revealed weaker PIQ in younger children which improved with age. The availability of NGS (new generation sequencing) techniques for systematic prenatal workup might decrease the anxiety of many couples currently dealing with the risk of bearing a child with a rare but severe syndromic form of ACC.

\section{Funding source}

This work was funded by grants from the French National Ministry of Health to the National Reference Center for Rare Diseases with Intellectual Disability, Lyon, France (Pr V des Portes). The authors have no financial relationships relevant to this article to disclose.

\section{Potential conflicts of interest}

The authors have no conflicts of interest relevant to this article to disclose.

\section{Contributors' statement}

Pr V des Portes designed the study, carried out the analyses, drafted the manuscript, revised the manuscript and approved the final manuscript as submitted.

Dr A Rolland and Dr AS Pellot extracted the data and carried out the initial analyses, and approved the final manuscript as submitted.

Mr J Velazquez-Dominguez and Mrs E Peyric performed all psychometric assessments and contributed to data analysis, and approved the final manuscript as submitted.

Dr A Curie performed statistical analysis and revised the manuscript, and approved the final manuscript as submitted.

Dr MP Cordier, Pr P Gaucherand, Dr J Massardier and Dr M Massoud included women in the study and reviewed the manuscript, and approved the final manuscript as submitted.

Pr F Rivier, Dr D Ville, Dr A Clément and Dr A Lacalm contributed to the radiological and clinical follow-up of ACC patients and revised the manuscript, and approved the final manuscript as submitted. 
Pr L Guibaud checked all US and MRI data, included MRI figures and critically reviewed the manuscript, and approved the final manuscript as submitted.

\section{Acknowledgements}

The authors thank Oliver Gubbay for language editing. We would especially like to thank the patients and families for their involvement in the clinical follow-up.

\section{R E F E R E N C E S}

1. Paul LK, Brown WS, Adolphs R, et al. Agenesis of the corpus callosum: genetic, developmental and functional aspects of connectivity. Nat Reu Neurosci 2007;8(4):287-99.

2. Glass HC, Shaw GM, Ma C, Sherr EH. Agenesis of the corpus callosum in California 1983-2003: a population-based study. Am J Med Genet A. 2008;146A(19):2495-500.

3. Sotiriadis A, Makrydimas G. Neurodevelopment after prenatal diagnosis of isolated agenesis of the corpus callosum: an integrative review. Am J Obstet Gynecol 2012;206. 337.e1-5.

4. Moutard ML, Kieffer V, Feingold J, et al. Agenesis of corpus callosum: prenatal diagnosis and prognosis. Childs Nerv Syst 2003;19:471-6.

5. Ramelli G, Zanda N, Wyttenbach M, Bronz L, Schnider A. The prognosis of agenesis of the corpus callosum might mostly be favourable. Swiss Med Wkly 2006;136(25-26):404-5.

6. Pisani F, Bianchi ME, Piantelli G, Gramellini D, Bevilacqua G. Prenatal diagnosis of agenesis of corpus callosum: what is the neurodevelopmental outcome? Pediatr Int 2006;48(3):298-304.
7. Chadie A, Radi S, Trestard L, et al. Neurodevelopmental outcome in prenatally diagnosed isolated agenesis of the corpus callosum. Acta Paediatr 2008;97:420-4.

8. Cignini P, D'Emidio L, Padula F, et al. The role of ultrasonography in the diagnosis of fetal isolated complete agenesis of the corpus callosum: a long-term prospective study. J Matern Fetal Neonatal Med 2010;23(12):1504-9.

9. Mangione R, Fries N, Godard P, et al. Neurodevelopmental outcome following prenatal diagnosis of an isolated anomaly of the corpus callosum. Ultrasound Obstet Gynecol 2011;37:290-5.

10. Moutard ML, Kieffer V, Feingold J, et al. Isolated corpus callosum agenesis: a ten-year follow-up after prenatal diagnosis (how are the children without corpus callosum at 10 years of age?). Prenat Diagn 2012;32(3):277-83.

11. D'Antonio F, Pagani G, Familiari A, et al. Outcomes associated with isolated agenesis of the corpus callosum: a metaanalysis. Pediatrics 2016;138(3):e20160445.

12. Isapof A, Kieffer V, Sacco S, et al. Impact of prenatal corpus callosum agenesis diagnosis on pregnancy outcome.

Evaluation of 155 cases between 2000 and 2006. Arch Pediatr 2010;17:226-32.

13. Guibaud L. Contribution of fetal cerebral MRI for diagnosis of structural anomalies. Prenat Diagn 2009;29(4):420-33.

14. Sattler JM, Dumont R. Assessment of children: WISC-IV and WPPSI-III supplement, coll. San Diego: J.M. Sattler Publisher; 2004.

15. Fratelli N, Papageorghiou AT, Prefumo F, Bakalis S, Homfray T, Thilaganathan B. Outcome of prenatally diagnosed agenesis of the corpus callosum. Prenat Diagn 2007;27:512-7.

16. Volpe P, Paladini D, Resta M, et al. Characteristics, associations and outcome of partial agenesis of the corpus callosum in the fetus. Ultrasound Obstet Gynecol 2006;27:509-16.

17. Siffredi V, Anderson V, Leventer RJ, Spencer-Smith MM. Neuropsychological profile of agenesis of the corpus callosum: a systematic review. Dev Neuropsychol 2013;38(1):36-57.

18. Malinger G, Ben-Sira L, Lev D, Ben-Aroya Z, Kidron D, LermanSagie T. Fetal brain imaging: a comparison between magnetic resonance imaging and dedicated neurosonography.

Ultrasound Obstet Gynecol 2004;23:333-40. 